\title{
Prediction of Strength of Remixed Concrete by Application of Orthogonal Decomposition, Neural Analysis and Regression Analysis
}

https://doi.org/10.1515/eng-2019-0053

Received May 16, 2019; accepted June 2, 2019

\begin{abstract}
Compressive strength is the foremost property of concrete which is influenced by a number of parameters. These parameters plays important role for the characteristics achieved by concrete. Orthogonal decomposition, neural analysis and regression analysis tools can be utilized where the dependence and independence of these parameters to be considered. In this paper these analyses are considered for remix concrete, in which apart from the cement contents, w/c ratio, proportions of C.A., F.A., the other parameters like blend ratio $\left(\mathrm{r}=\mathrm{Q}_{o} / \mathrm{Q}_{f}, \mathrm{Q}_{o}=\right.$ quantity of old partially set concrete, $\mathrm{Q}_{f}=$ quantity of fresh concrete) time lag ( time between preparation and placing of concrete) also plays the important role.
\end{abstract}

Keywords: Remixed concrete, blend ratio, time lag, orthogonal decomposition, neural analysis, regression.

\section{Introduction}

In the modern Civil Engineering construction work, concrete plays a vital role and is used very widely as a building material. It is composed of fine and coarse aggregates held together by a hardened paste of cement and water. It is generally considered that if this mixed mass is not immediately placed in the formwork and compacted without further loss in time, it starts to lose its strength. This partially set concrete if used in concreting reduces the strength of the structural elements. In construction partial setting of concrete occurs due to unforeseen circumstances like displacement of the formwork, power failure and breakdown of machinery, accidents and delay in casting due to time gaps, delay in transportation of concrete from RMC plant

K.L. Bidkar: K.K.Wagh Institute of Engineering Education \& Research, Nasik, India

Dr.P.D. Jadhao: K.K.Wagh Institute of Engineering Education \& Research, Nasik, India to project site location, due to extension of the incomplete construction on next day, due to shortage of constituents of concrete etc. A loss of strength is noticed if the concrete mass suffers setting due to considerable time lag between preparing the mix and it's placing. It is relevant to mention here that the strength and workability characteristics may not be affected appreciably up to the initial setting time but as the final setting time is approached they are greatly affected [1, 2].

The algorithms optimizing hybrid performance measures that seek to balance quantification and classification performance. The algorithms present a significant advancement in the theory of multivariate optimization, via a rigorous theoretical analysis, that they exhibit optimal convergence [3].

The mathematical model development is also possible by orthogonal decomposition [4, 5], saving time and computational work. Proper orthogonal decomposition (POD) is an accepted dimensionality reduction technique, which helps in hierarchizing the various influencing variables based on their variability.

Therefore, this technique is helpful in development of mathematical models that are operational and require less computational effort and time.

For the estimation of the compressive strength of concrete specimens an artificial neural network (ANN) using the experimental laboratory strength, and the ingredient values, their ratios is utilized in the study. Prediction of concrete compressive strength is implemented using ANN models, consisting of eleven input layer, one hidden layer and one output layer, for each data set. The analysis is then conducted for cube specimens with different compressive strengths for wide variation in their constituent proportions.

As compressive strength is utmost important property judging the levels of performance, the constituents of concrete and their relative importance should be considered. The statistical approaches are useful in predicting the strength of concrete [6]. 
The purpose of regression techniques are used to take data and deduce a response (y) or responses in terms of input variables ( $\mathrm{x}$-values).

Regression analysis is utilized to predict a continuous dependent variable or response from a number of independent or input variables. If the dependent variable is dichotomous, then logistic regression should be used. The independent variables used in regression can be either continuous or dichotomous (i.e. take on a value of 0 or 1). Categorical independent variables with more than two values can also be used in regression analyses, but they first must be converted into variables that have only two levels. This is called dummy coding or indicator variables. Usually, regression analysis is used with naturally-occurring variables, as opposed to experimentally manipulated variables, although you can use regression with experimentally manipulated variables. There are also the state-of-the-art regression methods, namely projection pursuit regression, support vector machines (SVM) and random forests [7]. In statistics, projection pursuit regression is a statistical model developed by Jerome $\mathrm{H}$. Friedman and Werner Stuetzle which is an extension of additive models. This model adapts the additive models in that it first projects the data matrix of explanatory variables in the optimal direction before applying smoothing functions to these explanatory variables [8]. Support vector machine (SVM) is firmly based on learning theory and uses regression technique by introducing accuracy insensitive loss function. SVM is one of the machine learning (ML) techniques derived from statistical learning theory by Vapnik and Chervonenkis [9]. The foundations of SVM were developed by Vapnik [10] at AT\&T Bell Laboratories. Overall, SVMs have been applied in statistics, computer science, and other fields with great success. Random forest is a great algorithm to train early in the model development process, to see how it performs and it's hard to build a "bad" Random Forest, because of its simplicity. This algorithm is also a great choice, if you need to develop a model in a short period of time. On top of that, it provides a pretty good indicator of the importance it assigns to your features. Random Forests are also very hard to beat in terms of performance. Of course you can probably always find a model that can perform better, like a neural network, but these usually take much more time in the development. And on top of that, they can handle a lot of different feature types, like binary, categorical and numerical. Random forests are a type of ensemble method which makes predictions by averaging over the predictions of several independent base models. Since its introduction by Breiman, the random forests framework has been ex- tremely successful as a general purpose classification and regression method [11].

\section{Related Work}

The work is carried out for twelve strength values along with the variables which affect the strength i.e. cement, $\mathrm{FA}, \mathrm{CA}$, water, blend ratio $\mathrm{r}$ and time lag $\mathrm{t}$ as the primary variables along with the derived variables water cement ratio $(\mathrm{W} / \mathrm{C})$, fine aggregate to cement ratio $(\mathrm{FA} / \mathrm{C})$, coarse aggregate to cement ratio $(\mathrm{CA} / \mathrm{C})$, blend ratio to cement ratio $(\mathrm{r} / \mathrm{C})$ and time lag to cement ratio $(\mathrm{t} / \mathrm{C})$. For developing the proposed model three different methods namely orthogonal decomposition, neural analysis and regression analysis are utilized.

\section{A) Orthogonal Decomposition}

Algorithm for POD [5, 12] has the following sequential steps in reorganizing and rationalizing data for subsequent use.

- Appropriate data attainment is the first step in orthogonal decomposition

- Checking for size, completeness and outliers for the data collected

- Creation of artificial variables from available data may be considered if established relationship exists, to reduce time and effort.

- Z-score standardization is a popular normalization.

$Z^{i}=\left(x^{i}-\ddot{x}^{k}\right) / \sigma^{k}$

$Z^{i}=$ Standardized variable

$\mathrm{x}^{i}=$ Original variable

$\ddot{x}^{k}=$ Variable mean

$\sigma^{k}=$ Standard deviation

$=\left[1 / \mathrm{N} \Sigma(\mathrm{xi}-\ddot{x} \mathrm{k})^{2}\right]^{1 / 2}$

$\mathrm{N}=$ Total no. of observations

$\mathrm{K}=$ Total no. of variables

- Assembling the correlation matrix for normalized. Checking for singularity, sample adequacy and sphericity of data.

- Eigen values and eigenvectors extraction from the correlation matrix. Eigenvectors designate the direction in which the greatest variations are seen. Eigen values quantify the relative amount of variation explained by the components. 
Table 1: Co-relation Matrix

\begin{tabular}{|c|c|c|c|c|c|c|c|c|c|c|c|c|}
\hline Co-relation & Strength & Cement & FA & CA & Water & $r$ & $\mathrm{t}$ & $w / C$ & $\mathrm{FA} / \mathrm{C}$ & $\mathrm{CA} / \mathrm{C}$ & $r / C$ & $t / C$ \\
\hline Strength & 1.000 & 1.000 & 1.000 & 0.999 & 0.999 & 0.999 & 0.999 & 0.999 & 0.996 & 0.9968 & 0.9967 & 0.9973 \\
\hline Cement & 1.000 & 1.000 & 1.000 & 1.000 & 0.999 & 0.999 & 0.999 & 0.999 & 0.9965 & 0.9965 & 0.9964 & 0.9970 \\
\hline FA & 1.000 & 1.000 & 1.000 & 1.000 & 0.999 & 0.999 & 0.999 & 0.999 & 0.996 & 0.9961 & 0.9960 & 0.9967 \\
\hline CA & 0.99 & 1.0000 & 1.000 & 1.000 & 0.998 & 0.999 & 0.999 & 0.999 & 0.9960 & 0.9959 & 0.9958 & 0.9966 \\
\hline Water & 0.9993 & 0.9992 & 0.999 & 0.998 & 1.000 & 1.000 & 1.0000 & 0.999 & 0.9988 & 0.9987 & 0.9986 & 0.9990 \\
\hline$r$ & 0.9994 & 0.9993 & 0.999 & 0.999 & 1.000 & 1.000 & 1.0000 & 1.000 & 0.9986 & 0.9986 & 0.9984 & 0.9989 \\
\hline t & 0.9995 & 0.9994 & 0.999 & 0.999 & 1.000 & 1.000 & 1.0000 & 1.000 & 0.9985 & 0.9985 & 0.9984 & 0.9988 \\
\hline$w / C$ & 0.9995 & 0.9994 & 0.999 & 0.999 & 0.999 & 1.000 & 1.0000 & 1.000 & 0.9984 & 0.9983 & 0.9982 & 0.9987 \\
\hline $\mathrm{FA} / \mathrm{C}$ & 0.9969 & 0.9965 & 0.996 & 0.996 & 0.998 & 0.998 & 0.9985 & 0.998 & 1.0000 & 1.0000 & 0.9999 & 0.9999 \\
\hline $\mathrm{CA} / \mathrm{C}$ & 0.9968 & 0.9965 & 0.996 & 0.995 & 0.998 & 0.998 & 0.9985 & 0.998 & 1.0000 & 1.0000 & 1.0000 & 0.9999 \\
\hline$r / C$ & 0.9967 & 0.9964 & 0.996 & 0.995 & 0.998 & 0.998 & 0.9984 & 0.998 & 0.9999 & 1.0000 & 1.0000 & 0.9999 \\
\hline$t / C$ & 0.9973 & 0.9970 & 0.996 & 0.996 & 0.999 & 0.998 & 0.9988 & 0.998 & 0.9999 & 0.9999 & 0.9999 & 1.0000 \\
\hline
\end{tabular}

- Correlation matrix is always a symmetric matrix, the eigen values are always real and eigenvectors are orthogonal to each other.

- Data reduction and hierarchization is done, based on the end objective of the exercise. Scree plots, eigen values and eigenvectors help in decision making as to how many axes need to be considered.

A total data of 12 variables is considered, out of which 7 are primary quantities and 5 are derived quantities. These are examined by orthogonal decomposition [12]. The Dependent variable strength is tested by comparing it with other quantities. For the data under consideration the corelation matrix is formed as shown in Table 1.The data is checked for non-sphericity as well as adequacy.

Total variance is extracted from, each component by PCA. The components eigen values as a total, percentage of variance as well as cumulative percentage for all the components are tabulated in Table 2. The only first two components have the major influence.

For squared loading these two components plays important role.

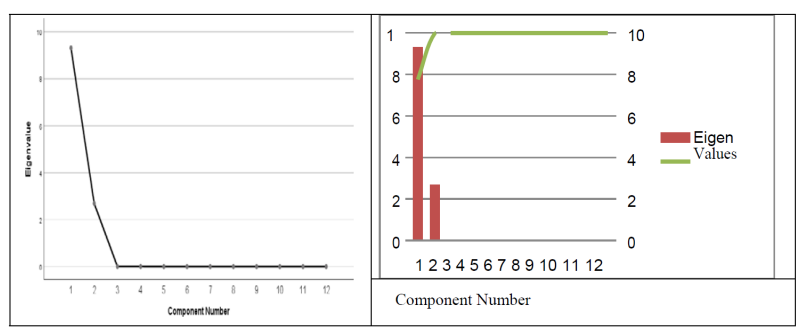

Figure 1: Plot of Components Vs Eigen Value
The plot for variation of eigen values with respect to the components shown in Figure 1, which elaborates the significance of components in the analysis. Figure shows that the slope of trend line is a steep fall down up to component 2. Next to component 2, the slope is not significant. Thus $99.95 \%$ of changes occurred by first two parameters (Table 1).

The data decomposition (Table 3) is done and the plot of parameters Vs component presented in Figure 2. This figure shows the relationship of various variables with respect to the components is plotted. It is observed that the strength and $\mathrm{W} / \mathrm{C}$ ratio are in different quadrants, which reveals that there is a reduction in strength with increase in water to cement ratio. This is consistent with the recognized Abram's law which states the strength of a concrete mix is inversely related to the mass ratio of water to cement. As the water content increases the strength of concrete decreases.

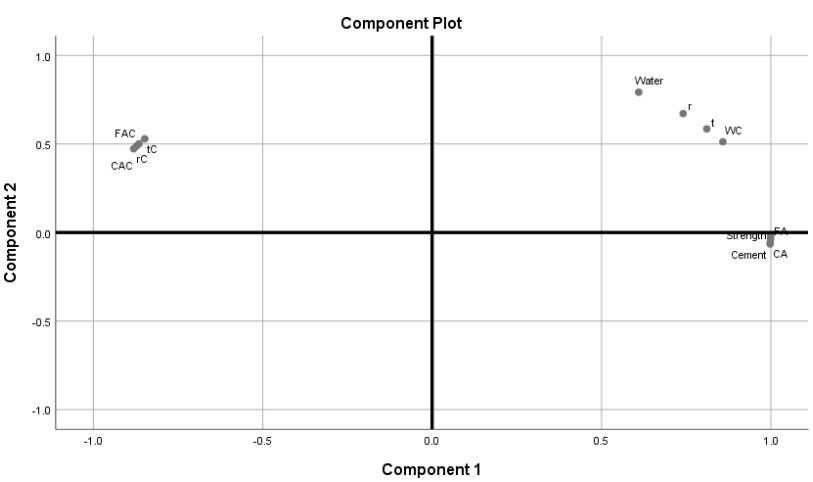

Figure 2: Variation of Parameters Vs Component 
Table 2: Total Variance using the Extraction Method, Principal Component Analysis

\begin{tabular}{lllllll}
\hline \multirow{2}{*}{ Component } & \multicolumn{2}{c}{ Initial Eigen values } & \multicolumn{3}{c}{ Extraction Sums of Squared Loadings } \\
\cline { 2 - 6 } & \multicolumn{1}{c}{ Total } & $\%$ of Variance & Cumulative \% & Total & \% of Variance & Cumulative \% \\
\hline 1 & 9.31 & 77.581 & 77.581 & 9.31 & 77.581 & 77.581 \\
2 & 2.684 & 22.37 & 99.951 & 2.684 & 22.37 & 99.951 \\
3 & 0.003 & 0.028 & 99.979 & & & \\
4 & 0.003 & 0.021 & 100 & & \\
5 & $1.69 \mathrm{E}-05$ & 0 & 100 & & \\
6 & $3.86 \mathrm{E}-08$ & $3.22 \mathrm{E}-07$ & 100 & & \\
7 & $2.65 \mathrm{E}-11$ & $2.20 \mathrm{E}-10$ & 100 & & \\
8 & $2.87 \mathrm{E}-12$ & $2.39 \mathrm{E}-11$ & 100 & & \\
9 & $8.60 \mathrm{E}-13$ & $7.16 \mathrm{E}-12$ & 100 & & \\
10 & $4.03 \mathrm{E}-14$ & $3.36 \mathrm{E}-13$ & 100 & & \\
11 & $1.45 \mathrm{E}-16$ & $1.21 \mathrm{E}-15$ & 100 & & & \\
12 & $-1.09 \mathrm{E}-16$ & & & & & \\
\hline
\end{tabular}

Table 3: Component Matrix using the Extraction Method, Principal Component Analysis

\begin{tabular}{lll}
\hline \multirow{2}{*}{ Parameters } & \multicolumn{2}{l}{ Component } \\
\cline { 2 - 3 } & 1 & 2 \\
\hline Strength & .999 & -.015 \\
Cement & .999 & -.034 \\
FA & .998 & -.055 \\
CA & .998 & -.065 \\
Water & .610 & .792 \\
r & .741 & .671 \\
t & .811 & .585 \\
W/C & .858 & .512 \\
FA/C & -.865 & .501 \\
CA/C & -.872 & .489 \\
r/C & -.881 & .473 \\
t/C & -.848 & .529 \\
\hline
\end{tabular}

Graphical representation of each parameter Vs all other parameters is given in Figure 3.

Normal P-P Plot of Regression Standardized Residual for Dependent Variable Strength is plotted as shown in Figure 4 By regression analysis the dependent variable strength is represented against its predicted values (Figure 5).

\section{B) Neural Network Analysis}

The 12 specimens are considered as trial specimens, amongst which 75\% (9 Nos) are considered for training and remaining 25\% (3 Nos.) used for testing purpose. The case processing summary for these specimens including the testing and training is shown in Table 4

The neural network [13] for input data and output data is represented in figure 6.The details of the network used is tabulated in Table 5

\section{Multilayer Perceptron [14]}

Table 4: Case Processing Summary

\begin{tabular}{cccc}
\hline & & $\mathrm{N}$ & Percent \\
\hline \multirow{2}{*}{ Sample } & Training & 9 & $75.00 \%$ \\
\cline { 2 - 4 } & Testing & 3 & $25.00 \%$ \\
\hline Valid & 12 & $100.00 \%$ \\
Excluded & 0 & \\
Total & 12 & \\
\hline
\end{tabular}

The Neural Analysis Model developed and it is summarized as shown in Table 6. It indicates Sum of squares error and relative error for testing and training data used. The various parameter estimates predicted are composed in Table 6, which indicates the values of component parameters for different layers under consideration.

The relationship of laboratory strengths and predicted strengths are plotted in Figure 7, which gives a linear relationship between these two strengths.

Figure 8 illustrates the importance of independent variables which are responsible for influencing the dependent variable (strength of concrete).These results also hold 


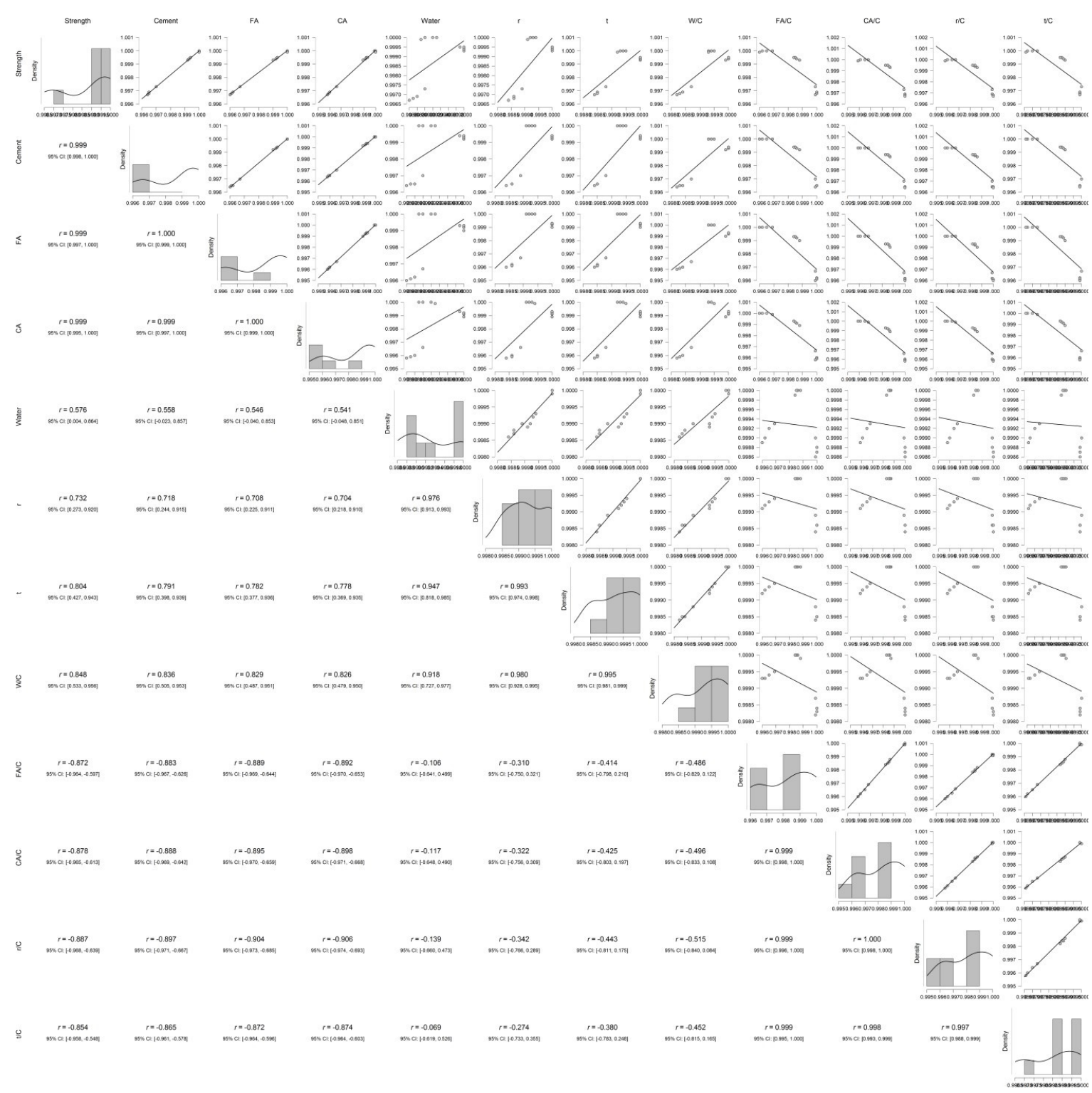

Figure 3: Scatter Plot of Parameters

good with the results investigated from figure 2 of decomposition analysis.

\section{C) Linear Regression}

Linear regression analysis is carried out for the observed compressive lab strength. The model compressive strength and the observed values of compressive strength are summarized in Table 8

\section{Model Development}

\section{Regression of variable Compressive Strength Model (MPa)):}

The goodness of fit statistics for the model is noted in Table 9 .

Table 10 shows the variance analysis for model strength with error involved

Computed against model $\mathrm{Y}=\operatorname{Mean}(\mathrm{Y})$

The parameters involved in the model developed from laboratory compressive strength is given in Table 11. From these observations the linear regression equation for model development can be derived. 
Table 5: Network Information

\begin{tabular}{|c|c|c|c|}
\hline \multirow{13}{*}{ Input Layer } & \multirow{11}{*}{ Covariates } & 1 & Cement \\
\hline & & 2 & $\mathrm{FA}$ \\
\hline & & 3 & CA \\
\hline & & 4 & Water \\
\hline & & 5 & $r$ \\
\hline & & 6 & $\mathrm{t}$ \\
\hline & & 7 & $W / C$ \\
\hline & & 8 & $\mathrm{FA} / \mathrm{C}$ \\
\hline & & 9 & $\mathrm{CA} / \mathrm{C}$ \\
\hline & & 10 & $r / C$ \\
\hline & & 11 & $\mathrm{t} / \mathrm{C}$ \\
\hline & Number of Units & & 11 \\
\hline & $\begin{array}{l}\text { Rescaling Method for } \\
\text { Covariates }\end{array}$ & & Standardized \\
\hline \multirow{3}{*}{ Hidden Layer(s) } & $\begin{array}{l}\text { Number of Hidden } \\
\text { Layers }\end{array}$ & & 1 \\
\hline & $\begin{array}{l}\text { Number of Units in } \\
\text { Hidden Layer } 1\end{array}$ & & 4 \\
\hline & Activation Function & & Hyperbolic tangent \\
\hline \multirow{5}{*}{ Output Layer } & $\begin{array}{l}\text { Dependent } \\
\text { Variables }\end{array}$ & & Strength \\
\hline & Number of Units & & 1 \\
\hline & $\begin{array}{l}\text { Rescaling Method for } \\
\text { Scale Dependents }\end{array}$ & & Standardized \\
\hline & Activation Function & & Identity \\
\hline & Error Function & & Sum of Squares \\
\hline
\end{tabular}

Table 6: Model Summary

\begin{tabular}{|c|c|c|}
\hline \multicolumn{2}{|r|}{ Sum of Squares } & 0.003 \\
\hline \multirow{4}{*}{ Training } & Error & \\
\hline & Relative Error & 0.001 \\
\hline & $\begin{array}{r}\text { Stopping Rule } \\
\text { Used }\end{array}$ & $\begin{array}{r}1 \text { consecutive step(s) } \\
\text { with no decrease in } \\
\text { error }\end{array}$ \\
\hline & Training Time & $00: 00.0$ \\
\hline \multicolumn{2}{|r|}{ Sum of Squares } & $4.18 \mathrm{E}-05$ \\
\hline \multicolumn{2}{|r|}{ Relative Error } & 0.001 \\
\hline Dependent Va & le: Strength & \\
\hline
\end{tabular}




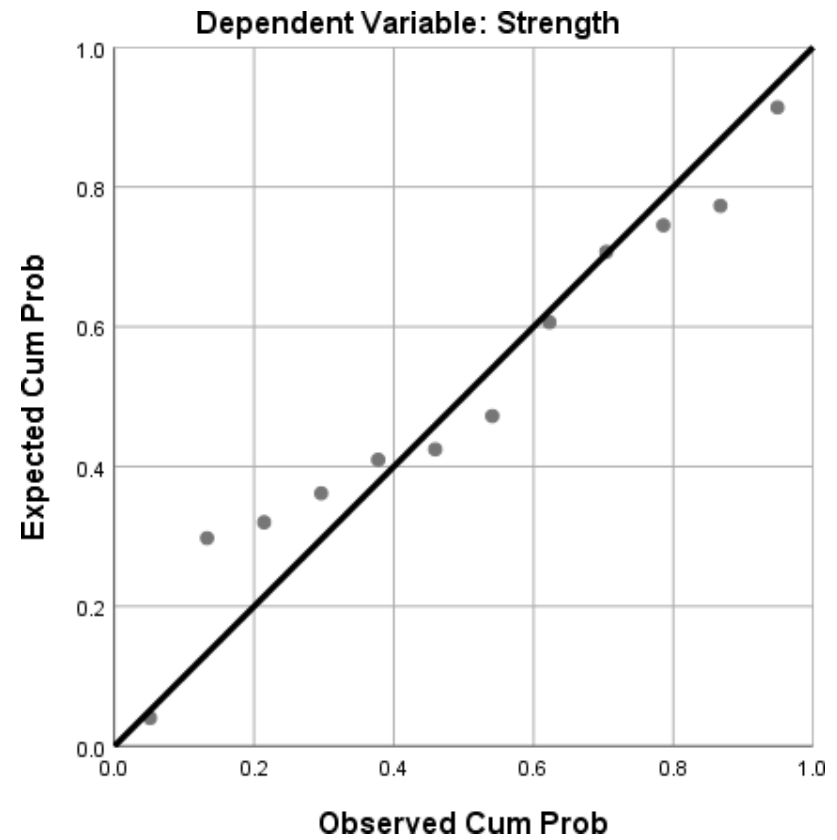

Figure 4: Normal P-P Plot of Regression Standardized Residual for Dependent Variable Strength

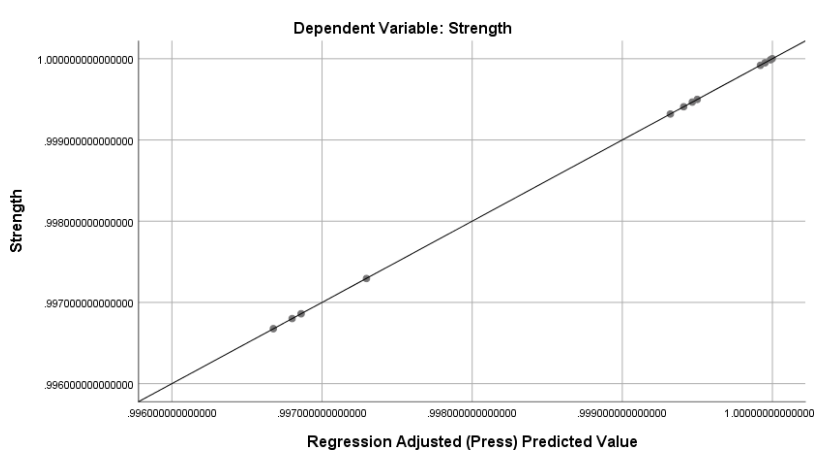

Figure 5: Regression adjusted for Dependent Variable Strength

Table 7: Independent Variable Importance

\begin{tabular}{lll}
\hline & Importance & $\begin{array}{l}\text { Normalized } \\
\text { Importance }\end{array}$ \\
\hline Cement & 0.13 & $63.10 \%$ \\
FA & 0.18 & $87.90 \%$ \\
CA & 0.205 & $100.00 \%$ \\
Water & 0.091 & $44.20 \%$ \\
$\mathrm{r}$ & 0.04 & $19.40 \%$ \\
$\mathrm{t}$ & 0.094 & $45.90 \%$ \\
W/C & 0.112 & $54.50 \%$ \\
FA/C & 0.049 & $23.80 \%$ \\
CA/C & 0.032 & $15.60 \%$ \\
r/C & 0.039 & $18.90 \%$ \\
t/C & 0.028 & $13.70 \%$ \\
\hline
\end{tabular}

二 Synaptic Weight $>0$
Synaptic Weight $<0$

Bias

Cement

FA

\section{CA}

\section{Water}

\section{(}

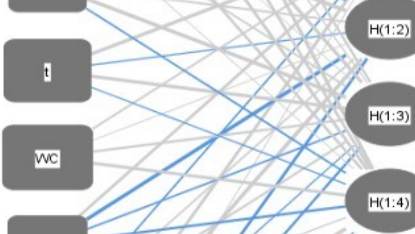

FAC

CAC

rc

tc

Hidden layer activation function: Hyperbolic tangen Output layer activation function: Identity

Figure 6: Neural Network [14]

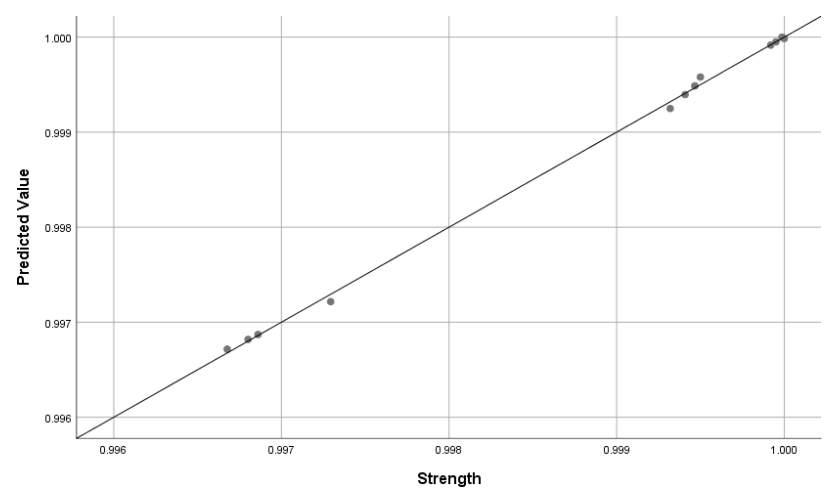

Figure 7: Laboratory Strength Vs Predicted Strength

Equation of the model (Compressive Strength Model (MPa)):

$\mathrm{Y}_{\text {Model }}\left(\mathrm{N} / \mathrm{mm}^{2}\right)=2.738678+0.904492^{\star} \mathrm{Y}_{\text {Lab }}\left(=\mathrm{Yp}-\mathrm{N} / \mathrm{mm}^{2}\right)$

From standardized coefficients of compressive strength of tabular results of Table 12, the graphical results are plotted in Figure 9. 
Table 8: Summary statistics

\begin{tabular}{cccccccc}
\hline Variable & Obs. & $\begin{array}{c}\text { Obs. with } \\
\text { missing } \\
\text { data }\end{array}$ & $\begin{array}{c}\text { Obs. } \\
\text { without } \\
\text { missing } \\
\text { data }\end{array}$ & Minimum & Maximum & Mean & $\begin{array}{c}\text { Std. } \\
\text { deviation }\end{array}$ \\
\hline $\begin{array}{c}\text { Compressive } \\
\text { Strength } \\
\text { Model (MPa) }\end{array}$ & 12 & 0 & 12 & 20.519 & 31.173 & 26.62 & 3.289 \\
\hline $\begin{array}{c}\text { Comp Strength } \\
\text { Lab(MPa) }\end{array}$ & 12 & 0 & 12 & 21.000 & 31.000 & 26.40 & 3.508 \\
\hline
\end{tabular}

Table 9: Goodness of fit statistics (Compressive Strength Model (MPa)

\begin{tabular}{|c|c|c|c|c|c|c|c|c|c|c|c|c|}
\hline Obs. & $\begin{array}{l}\text { Sum of } \\
\text { weights }\end{array}$ & DF & $\mathrm{R}^{2}$ & $\begin{array}{l}\text { Adjusted } \\
\mathrm{R}^{2}\end{array}$ & MSE & RMSE & MAPE & DW & $C p$ & AIC & SBC & PC \\
\hline 12 & 12 & 10 & 0.931 & 0.924 & 0.825 & 0.908 & 1.959 & 1.73 & 2.00 & -0.496 & 0.474 & 0.097 \\
\hline
\end{tabular}

Table 10: Analysis of variance (Compressive Strength Model (Mpa))

\begin{tabular}{llllll}
\hline Source & DF & $\begin{array}{l}\text { Sum of } \\
\text { squares }\end{array}$ & $\begin{array}{l}\text { Mean } \\
\text { squares }\end{array}$ & $F$ & Pr $>F$ \\
\hline Model & 1 & 110.718 & 110.718 & 134.20 & $<\mathbf{0 . 0 0 0 1}$ \\
Error & 10 & 8.250 & 0.825 & & \\
Corrected Total & 11 & 118.969 & & & \\
\hline
\end{tabular}

Table 11: Model parameters (Compressive Strength Model (Mpa))

\begin{tabular}{ccccccc}
\hline Source & Value & Standard error & $t$ & $\operatorname{Pr}>|t|$ & $\begin{array}{l}\text { Lower } \\
\text { bound } \\
(95 \%)\end{array}$ & $\begin{array}{l}\text { Upper } \\
\text { bound } \\
(95 \%)\end{array}$ \\
\hline Intercept & 2.739 & 2.078 & 1.318 & 0.217 & -1.892 & 7.369 \\
Comp. Strength Lab(MPa) & 0.904 & 0.078 & 11.58 & $<\mathbf{0 . 0 0 0 1}$ & 0.731 & 1.078 \\
\hline
\end{tabular}

Table 12: Standardized coefficients (Compressive Strength Model (MPa))

\begin{tabular}{|c|c|c|c|c|c|c|}
\hline Source & Value & $\begin{array}{l}\text { Standard } \\
\text { error }\end{array}$ & $\mathrm{t}$ & $\operatorname{Pr}>|t|$ & $\begin{array}{l}\text { Lower bound } \\
(95 \%)\end{array}$ & $\begin{array}{l}\text { Upper bound } \\
(95 \%)\end{array}$ \\
\hline Comp Strength Lab(MPa) & 0.965 & 0.083 & 11.58 & $<0.0001$ & 0.779 & 1.15 \\
\hline
\end{tabular}

The lab strengths and predicted model strength prediction along with the residuals statistics is tabulated in Figure 9.

The regression analysis is applied for model strength and its lab strengths are plotted in Figure 10. The representation of lab strength Vs the standardized residuals is shown in Figure 11

The representation of predicted model strength Vs model strength shows a better linear relationship is as shown in Figure 10.
The standardized residuals for each model strengths are graphically represented in Figure 11.

\section{Conclusions}

The data used for various analyses gives the conclusions as follows:

From Orthogonal Decomposition:

It is concluded that the compressive strength increases as cement content, CA and FA contents. It decreases with 
Table 13: Predictions and residuals (Compressive Strength Model (MPa))

\begin{tabular}{|c|c|c|c|c|c|c|c|c|c|c|c|c|}
\hline Obs. & Weight & $\begin{array}{l}\text { Comp } \\
\text { Strength } \\
\text { Lab } \\
\text { (MPa) }\end{array}$ & $\begin{array}{l}\text { Comp } \\
\text { Strength } \\
\text { Model } \\
\text { (Mpa) }\end{array}$ & $\begin{array}{l}\text { Pred } \\
\text { (Comp. } \\
\text { Strength } \\
\text { Model } \\
(\mathrm{MPa})) \\
\end{array}$ & Residual & $\begin{array}{l}\text { Std. } \\
\text { residual }\end{array}$ & $\begin{array}{l}\text { Std. } \\
\text { dev. } \\
\text { on } \\
\text { pred. } \\
\text { (Mean) } \\
\end{array}$ & $\begin{array}{l}\text { Lower } \\
\text { bound } \\
95 \% \\
\text { (Mean) }\end{array}$ & $\begin{array}{l}\text { Upper } \\
\text { bound } \\
95 \% \\
\text { (Mean) }\end{array}$ & $\begin{array}{l}\text { Std. } \\
\text { dev. } \\
\text { on } \\
\text { pred. } \\
\text { (Obs.) }\end{array}$ & $\begin{array}{l}\text { Lower } \\
\text { Bound } \\
95 \% \\
\text { (Obs.) }\end{array}$ & $\begin{array}{l}\text { Upper } \\
\text { bound 95\% } \\
\text { (Observation) }\end{array}$ \\
\hline 1 & 1 & 31.000 & 31.1 & 30.778 & 0.395 & 0.435 & 0.445 & 29.787 & 31.768 & 1.011 & 28.52 & 33.03 \\
\hline 2 & 1 & 30.700 & 30.4 & 30.507 & -0.079 & -0.087 & 0.426 & 29.558 & 31.455 & 1.003 & 28.27 & 32.74 \\
\hline 3 & 1 & 29.800 & 29.6 & 29.693 & -0.020 & -0.022 & 0.373 & 28.861 & 30.524 & 0.982 & 27.50 & 31.88 \\
\hline 4 & 1 & 29.400 & 29.2 & 29.331 & -0.036 & -0.040 & 0.351 & 28.548 & 30.114 & 0.974 & 27.16 & 31.501 \\
\hline 5 & 1 & 28.330 & 28.3 & 28.363 & -0.009 & -0.010 & 0.302 & 27.689 & 29.037 & 0.957 & 26.23 & 30.49 \\
\hline 6 & 1 & 27.200 & 27.0 & 27.341 & -0.322 & -0.355 & 0.269 & 26.740 & 27.941 & 0.947 & 25.23 & 29.45 \\
\hline 7 & 1 & 25.500 & 25.7 & 25.803 & -0.032 & -0.035 & 0.272 & 25.198 & 26.408 & 0.948 & 23.69 & 27.91 \\
\hline 8 & 1 & 25.100 & 25.1 & 25.441 & -0.262 & -0.288 & 0.281 & 24.815 & 26.068 & 0.951 & 23.32 & 27.56 \\
\hline 9 & 1 & 24.300 & 24.5 & 24.718 & -0.147 & -0.162 & 0.309 & 24.029 & 25.407 & 0.960 & 22.58 & 26.85 \\
\hline 10 & 1 & 22.600 & 22.4 & 23.180 & -0.706 & -0.777 & 0.396 & 22.298 & 24.063 & 0.991 & 20.97 & 25.38 \\
\hline 11 & 1 & 21.000 & 20.5 & 21.733 & -1.214 & -1.337 & 0.497 & 20.626 & 22.840 & 1.035 & 19.42 & 24.04 \\
\hline 12 & 1 & 21.90 & 24.9 & 22.54 & 2.43 & 2.67 & 0.439 & 21.57 & 23.52 & 1.009 & 20.30 & 24.79 \\
\hline
\end{tabular}

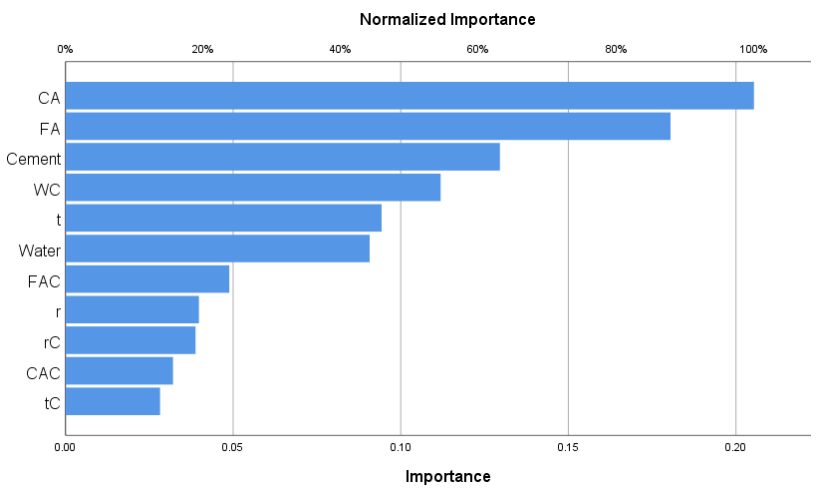

Figure 8: Importance of Independent Variables

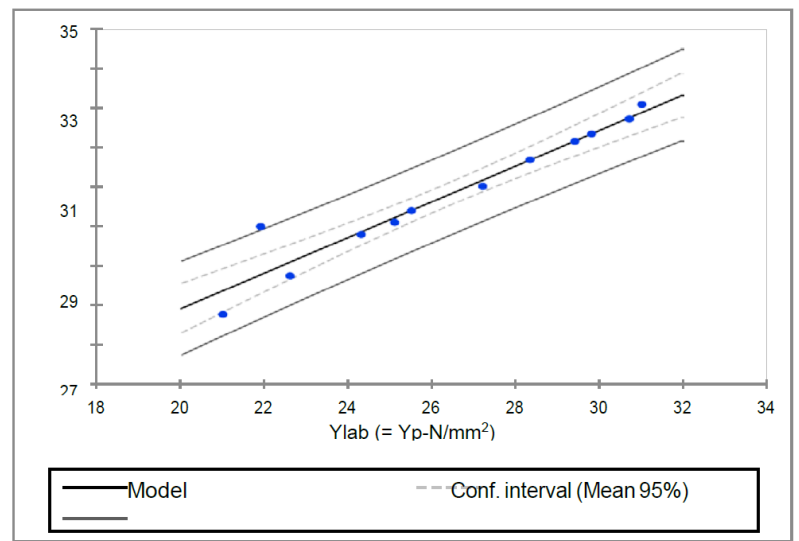

Figure 9: Regression of $\mathrm{Y}_{\text {Model }}\left(\mathrm{N} / \mathrm{mm}^{2}\right)$ by $\mathrm{Y}_{\text {Lab }}\left(=\mathrm{Yp}-\mathrm{N} / \mathrm{mm}^{2}\right)$ $\left(R^{2}=0.931\right)$

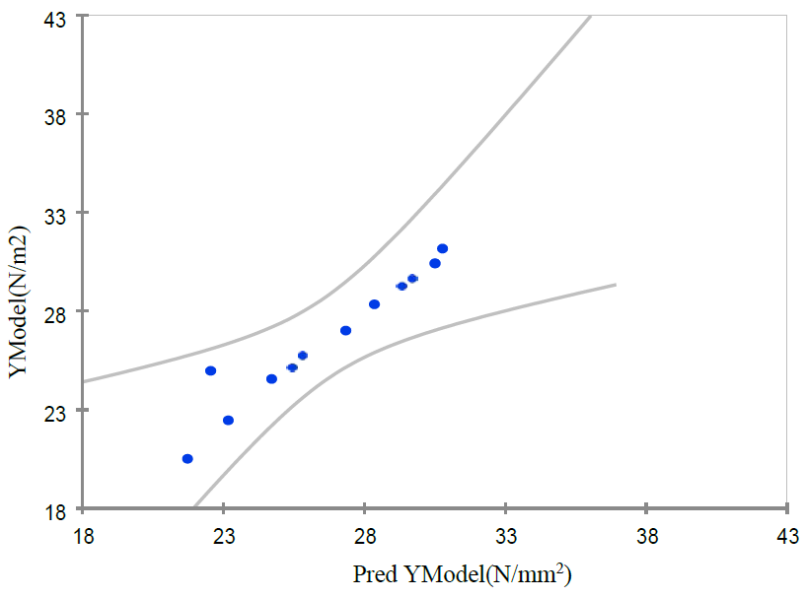

Figure 10: Pred $\left(\mathrm{Y}_{\text {Model }}\left(\mathrm{N} / \mathrm{m}^{2}\right) / \mathrm{Y}_{\text {Model }}\left(\mathrm{N} / \mathrm{m}^{2}\right)\right.$

increase in water content, blend ratio, time lag and W/C ratio (Figure 2)

It also decreases with the parameter's ratios like $\mathrm{W} / \mathrm{C}$, $\mathrm{CA} / \mathrm{C}, \mathrm{r} / \mathrm{C}, \mathrm{t} / \mathrm{c}$

\section{From Neural Analysis}

Figure 8 represents that the dependent variable strength is having the main influence of the parameters like C.A, FA, cement and $\mathrm{W} / \mathrm{C}$ ratio, while the other parameters like $\mathrm{t}, \mathrm{r}$, water, the ratios like $\mathrm{FA} / \mathrm{C}, \mathrm{r} / \mathrm{C}, \mathrm{CA} / \mathrm{C}, \mathrm{t} / \mathrm{C}$ are not so much significant.

\section{From Linear Regression}

From the lab compressive strength, the model strength can be predicted effectively $\left(R^{2}=0.931\right)$. 


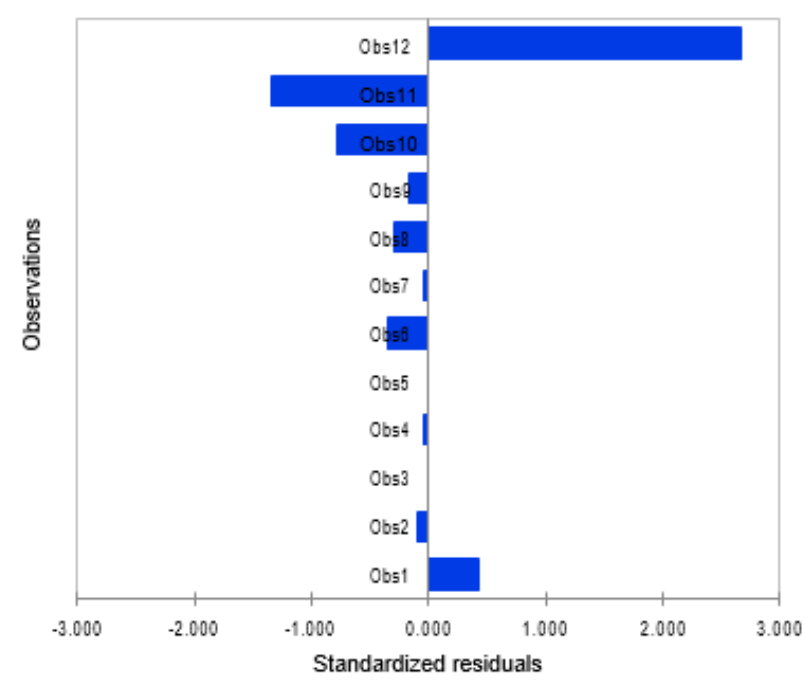

Figure 11: Standardized residuals $/ \mathrm{Y}_{\text {Model }} \mathrm{N} / \mathrm{m}^{2}$

The equation of the model formalized as, Y Model $\left(\mathrm{N} / \mathrm{mm}^{2}\right)=2.738678+0.904492^{\star} \mathrm{Y}_{\text {Lab }}\left(=\mathrm{Yp}-\mathrm{N} / \mathrm{mm}^{2}\right.$.

\section{References}

[1] A.A. Alnaki, F.M. Wegian, M.A. Abdalghafar, F.A. Alotaibi, Assessment of the Strength of Remixed Concrete Structures, Jordan Journal of Civil Engineering, 2014; 8(2):227-238

[2] A.M. Neville, Properties of concrete Fourth and Final Edition, in Perason-Prentice Hall, 2004.

[3] Kar, P., Li, S., Narasimhan, H., Chawla, S., \& Sebastiani, F. Online Optimization Methods for the Quantification Problem, 2016; 1625-1634
[4] Y.C. Liang, W.Z. Lin, H.P. Lee, S.P. Lim, K.H. Lee, H. Sun, Proper orthogonal decomposition and its applications - Part II: Model reduction for MEMS dynamical analysis, Journal of Sound 2002; 256(3):515-532

[5] M. Bartlett, J.G. MacGregor, Statistical analysis of the compressive strength of concrete in structures, $\mathrm{ACl}$ Materials Journal, 1996; 93(2): 158-16

[6] A. Sadrmomtazi, J. Sobhani, M.A. Mirgozar, Modeling compressive strength of EPS lightweight concrete using regression, neural network and ANFIS, International Journal of Optimization In Civil, 2019; 9(2):313-329

[7] Mendes-Moreira, J., Jorge, A. M., De Sousa, J. F., \& Soares, C. Comparing state-of-the-art regression methods for long term travel time prediction. Intelligent Data Analysis, 2012; 16(3), 427-449

[8] Friedman, J.H. and Stuetzle, W. Projection Pursuit Regression. Journal of the American Statistical Association, 1981; 76(376), 817-823

[9] V. Vapnik, A. Chervonenkis, V. Vapnik, A. Chervonenkis, A note on one class of perceptrons, Autom. Remote Control 2,(1964)

[10] V.Vapnik, The Nature of Statistical Learning Theory, SpringerVerlag Berlin, Heidelberg, ISBN:0-387-94559-8-1995.

[11] Leo Breiman (2001) “Random Forests" Machine Learning, 45, 532

[12] G. Kerschen, J.C. Golinval, A.F. Vakakis, L.A. Bergman, The method of proper orthogonal decomposition for dynamical characterization and order reduction of mechanical systems: An overview, Nonlinear Dynamics 2005; 41, 147-169.

[13] M. Nikoo, F. Torabian Moghadam, t. Sadowski, Prediction of Concrete Compressive Strength by Evolutionary Artificial Neural Networks, Advance Materials Science Engineering ,2015;1-8

[14] I.C. Yeh, Modeling of strength of high-performance concrete using artificial neural networks, Cement and ConcreteResearch,1998; 28(12), 1797-1808 